\title{
Managing Alumni-Alma Mater Relationship
}

\author{
R Natarajan* \\ Former Chairman, AICTE and Former Director, IIT Madras, India \\ *Corresponding Author: R Natarajan, Former Chairman, AICTE and Former Director, IIT Madras, India.
}

Received: January 22, 2022; Published: January 28, 2022

\section{Summary}

This paper looks at several facets of alumni-alma mater relationship and strategies for managing it for achieving success. It is recognized that nostalgia is the glue that can sustain the relationship, and continuous mutual communication is essential to keep alive the relationship. There are mutual expectations which must be carefully fulfilled. The driving forces for promoting the alumni-alma mater relationship and critical success factors should be recognized and nurtured. Regular Reunions, on campus and at the different alumni centers are necessary to maintain the momentum of the relationship.

\section{Introduction}

The alumni of educational institutions represent one of their important stakeholders and it is very important for the alumni-alma mater relationship to be managed in an enlightened and effective manner. While this happens routinely in the US, it is only recently that higher educational institutions in India have learned to recognize the alumni as important stakeholders who should be cultivated as contributors to the achievement of the mission of the institution.

The strength of the Relationship is a function of the success achieved by the Alumni; the credit they are prepared to ascribe to the contributions of the Alma Mater; the efforts made by each to keep in touch with the other. The relationship itself is rather tenuous, such as that between parents and children, as they grow up. The alumni must also remember that while they are important as stakeholders, they are supplementary stakeholders, in the sense that they should desist from involving themselves in mainstream activities such as selection of Director, duration of the Director's term, budgetary details, and determination of Institute priorities, as alumni of an institution in Bangalore were proposing to do recently.

While mutual communication is essential to keep alive the relationship, there are gaps in the process. Efforts are needed to make improvements in this area. With so many IT-enabled artifacts available, it must be possible to do better in this respect.

There are mutual expectations, which are ill-defined and diverse: the alumni expect the alma mater to constantly keep in touch with them; communicate with them; continuously enhance its reputation so that the alumni can be proud of their alma mater; and keep the feel-good factor at a peak all the time.

The alma mater expects the alumni to: feel proud and good about the contributions of the alma mater in providing a good foundation and initial conditions as the basis of their present success; constantly keep in touch with it; promote activities that will benefit the Institute, in both tangible as well as intangible ways; form cohesive groups in the cities they live in, and help each other, if and when necessary; and provide mentoring and counseling to current students.

There are several barriers to achieving success: time constraints (time for self and familyvs alumni activities); apathy / cynicism, in some cases; lack of communication; and history of some bad experiences.

Some of the strategies to overcome the barriers are: Institute Distinguished Alumnus Awards to honour the Alumni for their 
Achievements and Accomplishments; establish communication channels and continuously communicate and interact; and organize re-unions (gold, silver, pearl, etc.); re-unions are likes summit talks - adequate preparation is crucial.

Like in any partnership, or collaboration or joint activity, the following are essential for achieving the desired results: regular meetings, get-togethers, newsletters, chat sessions, e-groups; identification of nodal persons on either side, who provide a focus; mutual understanding and respect; clear articulation of goals and projected activities (e.g. Institute needs that alumni can fulfill); feedback, to re-orient or fine-tune plans; response - fast and precise (the world is full of impatient people!); broad-based participation - (we need numbers and scale.); leadership; involvement of current faculty and students ; good documentation of success stories; and learnings from Best Practices of others.

\section{Driving Forces for promoting the Alumni-Alma mater Relationship}

The driving forces exist on both sides - the Institution as well as the Alumni. On the institution side one can identify the following: Recognition of Alumni as important stakeholders; Institution's needs requiring alumni contributions; Feedback on academic as well as other relevant matters; technology collaboration; and infrastructure requirements.

On the Alumni side, we can identify: Nostalgia; recognition of contributions of alma mater in laying the foundation for current success; loyalty to alma mater; and patriotism towards India.

\section{Critical Success Factors}

The following can be identified as critical success factors for getting positive outcomes from the alumni-alma mater relationship: commitment and support of Director/Head of Institution, Deans and Heads of Departments; Identification of 'Champions' in the Institution who will drive the Relationship; Careful articulation of Institutional needs worthy of alumni support; Appropriate recognition of assistance provided; prompt and 'correct' response by the Institution; effective communication; documentation ; and bestowing importance to the 'feel-good factor 'on both sides.

\section{The Importance of Reunions}

Every Alumni Reunion is an opportunity for the alumni to turn the clock back and feel younger again -- in virtual time; to meet their classmates and friends, whom they have not seen for many years; to meet their teachers of yester-years and learn to appreciate them -- a lot more than they did as students; to showcase their Alma Mater to their spouses and children.

The Alumni Reunion is also an opportunity for the alma mater to feel proud of the alumni achievements and accomplishments, for which the Institute laid the foundation many years ago; to obtain valuable feedback from the alumni and also suggestions on how the Institute can serve its stakeholders better.

Over the years, the Institute has learnt many interesting things from such Reunions: The Reunion is an emotional experience for the alumni as well as for the Institute. The nostalgia the alumni feel has both space and time correlations: it is directly proportional to the distance between their home and the Institute, and the time elapsed since they left the portals of the Institute. Nostalgia is the glue that binds the alumni to their alma mater.

Most of the alumni acknowledge that they owe their success, at least in part, to their residence and studies at the Institute. They have more attachment to the hostels than to their departments. The undergraduates have more attachment to the alma mater than the postgraduates, not only because of their longer stay in the Institute, but also because they were younger when they were UGs. In fact, recent efforts by a predominantly postgraduate institution like the Indian Institute of Science have been less successful than the IITs, which are predominantly undergraduate institutes. The alumni feel that their teachers are better - much better - than they thought they were while they were students here! There is a generation gap between the alumni and the present students as there is between them and their children. They are keen to do something in return for the Institute, but the details need to be worked out. 
In conclusion, an excellent potential exists as Alumni Goodwill; but we must convert this latent potential into explicit support for the Institute, through positive processes.

Volume 2 Issue 2 February 2022

(C) All rights are reserved by $R$ Natarajan. 